\title{
0126 ROAD LOVE: A COMMUNITY PROJECT
}

G de Hoyos*, D Manoukian, J Ungaro, E Palero Correspondence: Subsecretara de Salud, Provincia de Neuquen. Personal: Aconcagua 290, Neuqun, Provincia de Neuquen. Work Address: Fotheringham 121, Neuquen, Provincia de Neuquen 8300, Argentina

10.1136/ip.2010.029215.126

Introduction Chos Malal is a town of about 17000 inhabitants situated in Northern Patagonia. Recent fatal vehicle collisions and membership to the Healthy Municipalities, Cities and Communities Network set in motion a training process for members of the Traffic Advisory Board and Health leaders, which led to the creation of a community project: Road Love.

Objective To describe the development of a participatory process to improve road safety in the community.

Materials and Methods Between June and July 2008 consecutive workshops were carried out in four sectors of the town seeking awareness, community diagnosis and collective proposals. Conclusions were presented to the community in September.

Results Many people participated. A risk map was obtained, vulnerable groups were identified, and actions were executed at all levels. The City Council passed several laws regarding traffic safety. Some leaders replicated workshops and teachers promoted school projects. Students started radio campaigns on road safety. People designed and distributed leaflets and messages. Improvements in infrastructure and signalling were carried out. The number of traffic injured people dropped $28 \%$ in the first 8 months compared to the same period the previous year. No serious or fatal victims were recorded during this period. Following community's recommendations, a second project regarding traffic injuries surveillance is being executed. Discussion and Conclusions Local participatory diagnosis, networks reinforcement and advocacy from health sector are crucial to start cultural changes. Peoples commitment to support community values increase social capital and makes sustainability possible. 